\title{
La Formación Humanista en el diseño curricular de la Universidad Autónoma de Aguascalientes
}

Azucena Fabiola Murillo Vega

"El ser humano, al tener un diálogo consigo mismo, intenta unirse a su naturaleza".

Liliana Weinberg

T a Formación Humanista, en el diseño curricular de la Universidad ـAutónoma de Aguascalientes, es una invitación a descubrir el ser humano que todos llevamos dentro por medio de la educación formalizada. La visión al año 2015 de la Institución vislumbra una docencia que:

...tiene como propósito formar integralmente y con alto sentido humanista, a los estudiantes en programas y procesos educativos de alta calidad reconocidos nacional e internacionalmente, de esta forma, los egresados son altamente competentes y contribuyen de forma efectiva al desarrollo sustentable de su entorno... (UAA, 2008: 110).

Para ello, las ideas que surgen en la actualidad sobre el diseño curricular van acompañadas de lo que se denomina competencias. Sobre éstas, Zabala menciona que corresponde al campo de las actitudes, los procedimientos y los conceptos "las competencias escolares deben abarcar el ámbito social, interpersonal, personal y profesional" (2007: 15). También nos dice que el aprendizaje de una competencia se encuentra lejos de lo que es el aprendizaje mecánico, puesto que la competencia implica el "mayor grado de significancia y funcionalidad posible, ya que para poder ser utilizada deben tener sentido tanto la propia competencia como sus componentes procedimentales, actitudinales y conceptuales" (Zabala, 2007: 15).

Si el término competencia nace como producto de que el aprendizaje memorístico de los conocimientos no puede ser aplicado en la vida real, las competencias deben centrarse entonces a lo que se relaciona con las necesidades del ser humano como bien dice Zabala: "los fines de la educación en competencias son el pleno desarrollo de la persona" (2007: 65).

La educación formalizada es un derecho y el más sublime de los procesos, posee la intencionalidad de promover la realización de un ideal de formación, ya que la formación de seres humanos es el más grande reto y compromiso de la UAA al desear la promoción de la persona que funciona integralmente. Más allá de ofrecer una educación centrada en los conocimientos, la Institución tiene el compromiso de priorizar la Formación Humanista, la cual tiene como finalidad que los seres humanos logren un aprendizaje significativo en verse a sí mismos 


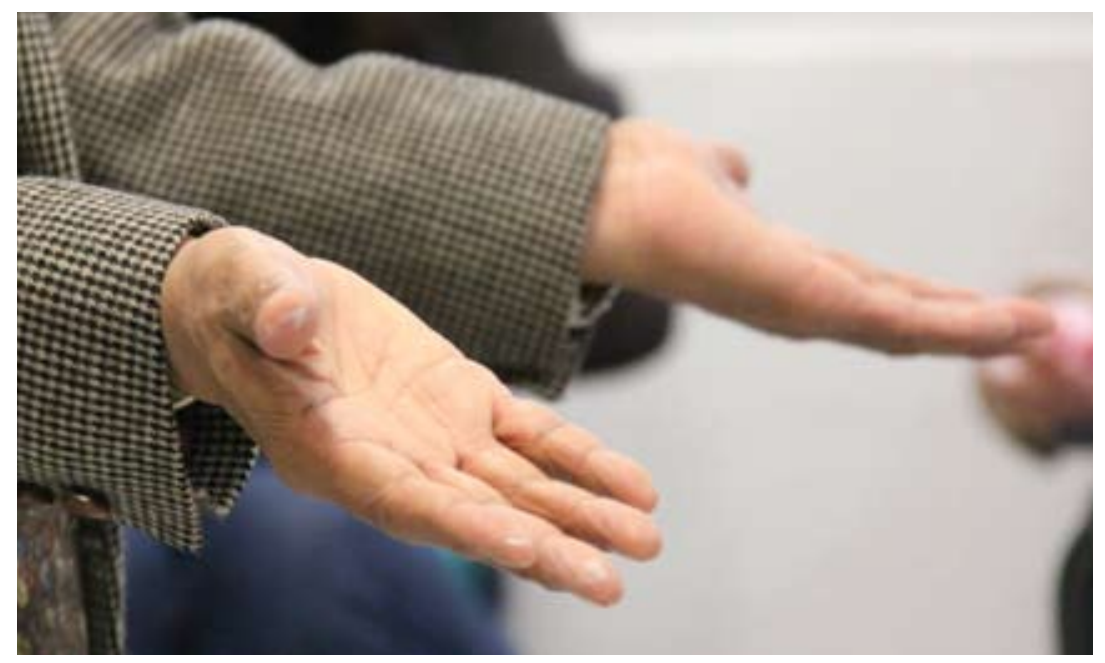

y aceptarse plenamente, aceptar sus sentimientos y tener confianza, así como imponerse sus propias orientaciones, ir caminando por la vida siendo cada vez más parecido a lo que quieren llegar a ser.

La Formación Humanista debe lograr que las percepciones de sí mismo se vayan transformando en el sentido en que las proyectamos, lograr que cada persona se haga responsable de sí misma y pueda realizar su propio proyecto personal.

Para responder a la visión que la misma Institución plantea, debe formar hombres y mujeres capaces de enfrentar la vida, no sólo con un bagaje teórico enfocado a su formación y experiencia profesional, sino que incluya también habilidades, actitudes y valores que les permitan vivir de manera integral en el mundo que les rodea y que, con el ejercicio de su profesión, transformen la sociedad aguascalentense.

La Universidad trabaja para que el diseño curricular en la competencia del ámbito personal e interpersonal esté directamente relacionado con la Formación Humanista, la cual debe "facilitar en los estudiantes el proceso de desarrollo de sí mismo en servicio de los demás, mediante la reflexión de actitudes y conductas con la finalidad de armonizar una íntima relación entre su realización como ser humano y el ejercicio de su profesión" (Murillo, 2009: 69).

\section{Según Alfieri:}

mediante la profesión -que se posee, se ejerce y a la que se pertenece-, el individuo tiene la invaluable posibilidad de realizarse como ser humano, de desplegar sus talentos y desarrollarlos al máximo; la profesión es, pues, una fuente maravillosa de realización personal y de satisfacción humana, es un verdadero tesoro, tanto para quien la ejerce como para quienes reciben sus beneficios directa o indirectamente (2007: 22).

La finalidad de la Formación Humanista es más un movimiento de conciencia que un contenido o una idea, con la intención de ayudar a que los estudiantes sean conscientes de que, primero y ante todo, deben reconocerse como seres humanos y, a partir de ahí, conformar su identidad de tal manera que, si los estudiantes logran descubrir quiénes son y su valor como seres humanos, tendrán herramientas para vivir la vida a plenitud y ejercer su profesión con calidad humana y trasformar la sociedad. 


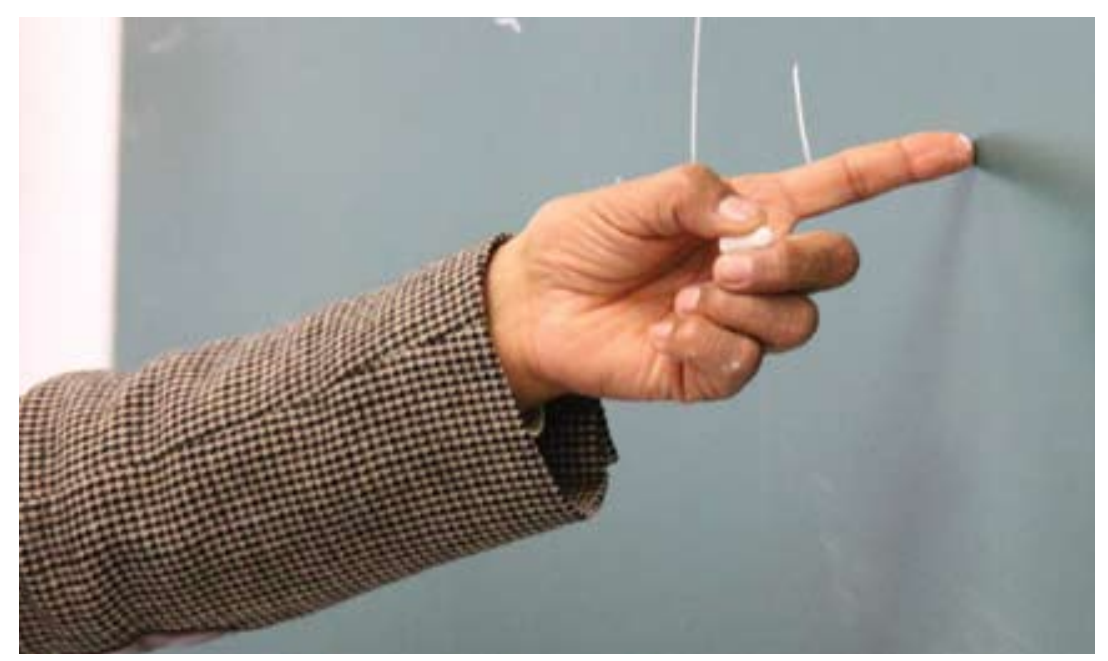

Llegar a convertirse en un ser humano tiene una connotación más elevada que el sólo ser un individuo o un ciudadano; estos últimos rasgos los adquirimos por el hecho de estar vivos e inmersos en una sociedad. La calidad de ser humano está relacionada con la toma de conciencia de concebirse y asumirse como seres humanos. ¿Qué tiene el ser humano para ser feliz?, ¡se tiene a sí mismo y a su naturaleza! ¿Cuál es la naturaleza más humana?, la que se muestra en la relación con el otro.

Los profesores deben promover el crecimiento de la conciencia y el ejercicio de la libertad en los estudiantes, ya que éstos son rasgos que nos dan el valor de seres humanos. La pérdida de estos rasgos es sinónimo de deshumanización. Ayudar a descubrir al ser humano que hay en los estudiantes es una tarea pendiente del desarrollo de las competencias en el ámbito personal e interpersonal. Los profesores, en el proceso de reflexión de reconocerse como seres humanos, se hacen cada vez más humanos, son ellos quienes facilitan los medios para el desarrollo integral de su propio ser humano en los estudiantes, son quienes promueven la realización de todas las potencialidades de cada estudiante, lo que quiere decir que los profesores tienen la encomienda de ir más allá de la transmisión de conocimientos y entrar a la promoción del desarrollo de habilidades del hacer y pensar, en el de los valores para decidir y vivir la vida con plenitud y calidad. Son ellos quienes, con su actitud permanente de reflexión, transformación, autocorrección y enriquecimiento, logran el desarrollo de todas las potencialidades humanas de sí mismos y de los estudiantes, es decir, educan a los estudiantes. Según López (2000: 13) educar en el campo del desarrollo humano es aceptar ciertos elementos como:

66 1 La educación se realiza en el ámbito de la libertad.

2 La educación se verifica en el diálogo con el otro (los otros).

3 El hombre (y la humanidad) es un ser que se va construyendo, haciendo a sí mismo.

4 La educación involucra al hombre en su totalidad lo mismo que a todos los hombres.

5 Finalmente, la educación (escolarizada) es un ámbito en el que se produce una intervención cuya finalidad última es el desarrollo humano ${ }^{\prime}$. 


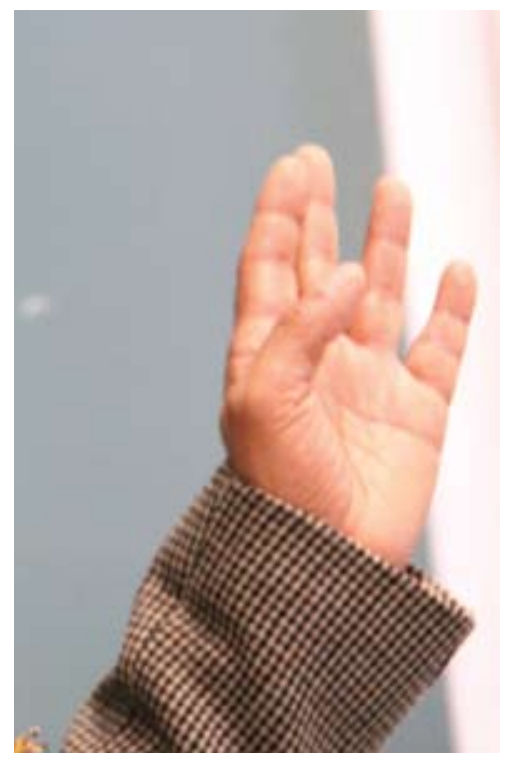

En tal sentido, el Modelo Educativo Institucional (MEI) describe los rasgos y tareas de los profesores de la Institución, con la finalidad de actualizar un docente con perfil humano que promueva una Formación Humanista en los estudiantes a quienes atiende, independientemente de los programas educativos a los cuales pertenezcan, con la intención de ser primero un ser humano y lo demás vendrá por añadidura. En este sentido, el MEI indica que los docentes "promueven actitudes favorables para el aprendizaje así como el desarrollo de la autoestima positiva en los estudiantes" (UAA, 2008: 42). De tal manera que los profesores deben reflexionar sobre su práctica docente, promoviendo una retroalimentación efectiva sobre el aprendizaje desarrollado en los estudiantes.

\section{Bibliografía}

Alfieri Casalegno, Adriana. (2007). Pensar la profesión su valor y sus valores. México: UAA.

López Calva, J.M. (2000). Desarrollo humano y práctica docente. México: Trillas.

Murillo, Azucena. (2009). Propuesta para evaluar los cursos de Formación humanista en la UAA. Tesis para obtener el grado de Maestra en Educación. México: Universidad Autónoma de Aguascalientes.

Universidad Autónoma de Aguascalientes. (2008). Plan de Desarrollo Institucional 2007-2015... Hacia un Renovado Horizonte. México: UAA.

Zabala, Antoni. (2007). 11 ideas clave cómo aprender y enseñar competencias. México: Graó. 